\title{
The Outcome of Preoperative Transfusion Guideline on Sickle Cell Disease Patients at King Fahd Hospital-Jeddah (KSA)
}

Sameera MR Felemban ${ }^{1,2 *}$, Rekha Bajoria², Amani Alsawaf ${ }^{1}$, Ratna Chatterjee ${ }^{2}$ and Abdulelah I Qadi ${ }^{1}$

${ }^{1}$ King Fahd Hospital, Jeddah, Saudi Arabia

2Institute for Women's Health, UCL, UK

\begin{abstract}
Background: We developed a local hospital preoperative transfusion guideline for sickle cell disease (SCD) patients to reduce the perioperative and the postoperative complications. This study was conducted to evaluate the outcome of clinical practice on SCD patients undergoing surgeries in our institution.
\end{abstract}

Methods: A retrospective review of 75 SCD patients undergoing surgery at King Fahd Hospital, Jeddah, Saudi Arabia was conducted between April 2005 and May 2010. The medical records were reviewed to define the perioperative risks and the postoperative complications in relation to the type of transfusion modality selected.

Results: The medical records of 75 SCD patients who underwent surgeries were reviewed to define the perioperative risks and the postoperative complications in relation to the type of transfusion modality selected. Preoperatively, 25.3\% had complete exchange transfusion (CETX), $17.3 \%$ had partial exchange transfusion (PETX), $26.7 \%$ had simple top up transfusion (STX) and $30.7 \%$ did not require transfusion (NTX). The postoperative complications included vasoocclusive crises (VOC) in $20 \%$, acute chest syndrome (ACS) in $2.7 \%$, and fever in $16 \%$ cases. $33.3 \%$ patients required the prolonged period of the hospital stay. In the patients of our study, postoperative fever, VOC, ACS, and the length of hospital stay did not show any difference regardless of types of transfusion modalities. However, the correlation was highly significant between the pre-operative haemoglobin $(\mathrm{Hb})$ level and postoperative fever $(P<0.01)$ and VOC $(\mathrm{P}<0.01)$.

Interestingly, SCD patients who received hydroxyurea had less postoperative complications such as fever $(P<0.05)$ and vaso-occlusive crises $(\mathrm{P}<0.05)$, while those who received prophylactic heparin in the postoperative period had a reduced length of hospital stay $(P<0.01)$ and vaso-occlusive crises $(P<0.01)$.

Conclusion: The guidelines for preoperative transfusion in SCD patients were effective in reducing the postoperative morbidity and mortality. Moreover, this guideline emphasises the operative situations where preoperative transfusion is needed and optimum regimen is required for different surgical operations sub-types.

Keywords: Patient; Acute chest syndrome; Occlusive crises; Mortality; Transfusion reaction

\begin{abstract}
Abbreviations
ACS: Acute Chest Syndrome; ANC: Absolute Neutrophil Count; BM: Bone Marrow; CETX: Complete Exchange Transfusion; CBC: Complete Blood Count; DNA: Deoxyribonucleic Acid; ETX: Exchange Transfusion; FNHTR: Febrile Non Hemolytic Transfusion Reaction; Hb: Hemoglobin; Hb A: Hemoglobin A; Hb C: Hemoglobin C; HBEP: Hemoglobin Electrophoresis; Hb F: Hemoglobin F; Hb S: Hemoglobin S; HPLC: High Performance Liquid Chromatography; HU: Hydroxyurea; I \& D: Incision and drainage; KFH: King Fahd Hospital; KSA: Kingdom of Saudi Arabia; Lap Chloe: Laparoscopic Cholecystectomy; LDH: Lactate Dehydrogenase; No TX: No Transfusion; NO: Nitric Oxide; NS: Not Significant; OR: Operation; ORIF: Open Reduction with Internal Fixation; PETX: Partial Exchange Transfusion; RCT: Randomized Control Trial; SCD: Sickle Cell Disease; SCT: Sickle Cell Trait; SD: Standard Deviation; STX: Simple Top up Transfusion; THR: Total Hip Replacement; TX: Transfusion; VOC: Vaso-Occlusive Crises
\end{abstract}

\section{Introduction}

\section{History of sickle cell disease}

Sickle cell disease (SCD) is an autosomal recessive disorder that is characterised by a substitution of thymine for adenine in the sixth codon of the beta gene ( $G A G \rightarrow G T G)$, which encodes valine instead of glutamic acid in the sixth position of the beta-globin formation. This leads to a malformation of the beta-globin component of haemoglobin known as haemoglobin $S(\mathrm{HbS})$ [1,2]. The "peculiar elongated and sickle-shaped" red blood cells which represent $\mathrm{Hb} \mathrm{S}$, was first discovered and described in 1904 in a dentistry student in Chicago, when his blood sample was examined by Dr. James B. Herrick. This observation was the beginning of identifying the underlying cause of the sickle cell disease (SCD) [3].

The inheritance of haemoglobin $\mathrm{S}(\mathrm{HbS})$ can be associated with a concurrent mutations in the beta globin gene that can also lead to an under-production of beta-globin. Additionally, a separate yet often co morbid disorder of thalassaemia [2] or other structural abnormality like $\mathrm{Hb} \mathrm{D}, \mathrm{Hb} \mathrm{C}$ or $\mathrm{Hb} \mathrm{E}$ [4]. Homozygote (SS) will show clinical symptoms of sickle cell disease (SCD), while the heterozygote (AS) or traits are usually asymptomatic. The occurrence of sickle cell trait (SCT) leads to a much higher prevalence of the gene in the gene pool due to a lack of symptom presentation and much longer lives without treatment compared to those who present with symptoms [5].

*Corresponding author: Sameera MR Felemban, King Fahd Hospital Jeddah, Saudi Arabia, Tel: +966 12660 6111; Fax: +966 (12) 665-7200; E-mail: smfelemban@yahoo.com

Received March 17, 2017; Accepted March 31, 2017; Published April 05, 2017

Citation: Felemban SMR, Bajoria R, Alsawaf A, Chatterjee R, Qadi Al, et al (2017) The Outcome of Preoperative Transfusion Guideline on Sickle Cell Disease Patients at King Fahd Hospital-Jeddah (KSA). J Blood Disord Transfus 8: 381. doi: 10.4172/2155-9864.1000381

Copyright: ( 2017 Felemban SMR, et al. This is an open-access article distributed under the terms of the Creative Commons Attribution License, which permits unrestricted use, distribution, and reproduction in any medium, provided the original author and source are credited. 


\section{Epidemiology of sickle cell disease}

Sickle cell anemia is one of the commonest diseases inherited due to haemoglobin disorder in the world [6]. It affects around 70,000 people and 12,000 people in USA and in UK, respectively [7]. It is the most prevalent hemoglobin disorder in other part of the world including sub-Saharan Africa, the Middle East the Mediterranean Basin, southern India and also South America. [8,9] The prevalence of SCD in Saudi Arabia is high in the eastern and southern regions of the country, and it is believed that $1.7 \%$ of populations of the Eastern Province were affected [10].

\section{Pathophysiology of SCD}

There are several factors that provoke sickling process which include stress, hypoxia, acidosis, and infection. These factors play a role through interleukins, vasoconstriction, nitric oxide (NO) and hypoxia. When the red cell is exposed to these factors it undergoes conformational changes leading to polymerization and formation of the sickle shape. The polymerized red cell is rigid, un-deformable, easily haemolysed and have a tendency to become trapped in capillaries due to adhesion to vascular endothelium. This would subsequently cause obstruction of blood flow by small vessel occlusion and endothelial damage [11-13]. The result of sickling process leads to a wide spectrum of disorders in sickle cell anaemia which vary according to the degree of anaemia, frequency of crises, extent of organ injury, and duration of survival [1].

\section{Clinical presentation and complications of SCD}

The clinical picture of sickle cell disease is characterised by anaemia and vasculopathy. This would be the underlying cause for painful vaso-occlusive crises, acute chest syndrome, infection, severe anaemia and multi-organ failure which are the major causes of morbidity and mortality $[2,8]$.

Acute chest syndrome, for example, results from a combination of low oxygen and reduced blood flow to the lungs causing severe respiration difficulties [13]. Sequestration crises occur when sickled cells gather in the spleen, especially in young children, causing enlargement. Both hypersplenism and lack of functional spleen could eventually lead to death either from additional infections or through sudden and profound anemia brought on by the spleen enlargement $[1,13]$.

Infections can also occur as a result of reduced splenic function, while general organ failure due to reduced blood flow and/or lack of oxygen supply can also trigger mortality and is a fairly common complication [2].

\section{Investigation and diagnosis of SCD}

Full blood count (including reticulocyte count) and blood films are essential for diagnosis of any anaemia. Other specific tests for haemoglobinopathies which are important for preliminary diagnosis and monitoring of therapy all have a place in screening of "at risk" patients. These include two "wet preparations" for sickling and sickle solubility test, electrophoresis (capillary, cellulose, alkaline, and acid), HbA2 analysis by microcolumn, high performance liquid chromatography (HPLC), estimation of $\mathrm{Hb} F$ (Betke method), immunoassay, and DNA analysis.

\section{Transfusion requirement in SCD}

Blood transfusion is one of the effective modalities of treatment in sickle cell disease but it is reserved in selected cases because of its hazards. The indications of transfusion in sickle cell disease include severe anaemia, progressive organ damage, and certain severe acute vaso-occlusive events $[5,14]$. Preoperative blood transfusion is another indication which helps to dilute the sickled red blood cells and increase the level of oxygen in blood preventing perioperative complications. There is no consensus, however, on the best regimen of preoperative transfusion. However, even when correctly used, these are not without complications $[6,8,15]$.

Blood transfusion can be given as a simple additive procedure (simple "top up" transfusion (STX)) to bring total haemoglobin level to $10 \mathrm{~g} / \mathrm{dl}$ or above, or exchange transfusions (ETX) using a manual or an automated cell separator method to reduce the haemoglobin $S$ level. The volume of blood to be transfused can be calculated using the following formula: Volume of RBCs $(\mathrm{mls})=(\mathrm{Hbd}-\mathrm{Hbs}) \times$ weight $(\mathrm{kg}) \times \mathrm{K}^{*}$. However, $\mathrm{K}^{\star}$ is a constant depending on haematocrit of blood to be transfused. It is 3 if packed red cells are used, 4 if plasma reduced blood and 6 if whole blood is used. Hbd represent the desired haemoglobin $(\mathrm{g} / \mathrm{dl})$, and Hbs is starting haemoglobin $(\mathrm{g} / \mathrm{dl})[11]$.

Transfusion related complications can be reduced by using leucodepleted, blood, in extended red cell phenol-typing before starting transfusion. The use of fresh blood to minimize alloimmunisation, febrile non-haemolytic transfusion reaction (FNHTR). Also, the use of ethnically matched blood and match blood for all Rh antigens and Kell, wherever possible would minimize alloimmunisation [12-16].

\section{The need of surgery in SCD}

Sickle cell disease (SCD) patients frequently require surgical procedures during their lifetime due to risk of complications. Cholecystectomy is the most common surgical procedure performed on sickle cell patients. It results from the tendency of SCD patients to form large and pigmented gallstones, which can cause immense pain and are potentially life threatening [17]. Other common surgeries include total hip replacement, adeno-tonsellectomy, and splenectomy. Some of these surgeries, especially splenectomies and cholecystectomies can now be performed laproscopcally, to reduce blood loss during the operations thus minimizing risks of the drop in blood volume added to the already-low oxygen saturation in many individuals with sickle cell disease $[15,18]$.

When SCD patients are compared to the general population, the observational studies from 1970s to 1980s on sickle cell disease patients undergoing surgery showed a poorer outcome, with the acute chest syndrome being the leading cause of death in these cases [19]. The Cooperative study of SCD showed that preoperative transfusion can reduce postoperative complications [20]. The role of careful fluid management, good oxygenation and meticulous postoperative care was shown to prevent the postoperative respiratory complications [14].

\section{Role of hydroxyurea in sickle cell disease}

A highly effective though still scantily-prescribed treatment for sickle cell disease is hydroxyurea, has multiple effects on blood cell types and counts and has a significant impact on the symptoms of sickle-cell anemia [21]. Hydroxyurea is given orally which increases the production of fetal hemoglobin ( $\mathrm{Hb} \mathrm{F}$ ) and the overall concentration of hemoglobin in the blood, the mean corpuscular volumes allowing for an increased blood flow. Additionally it decreases white blood cell count, absolute neutrophil count (ANC), absolute reticulocyte 
count, and lactate dehydrogenase (LDH) as well reducing the harmful deformability's in red blood cells, the hallmark of sickle cell disease [21]. Despite these positive effects and the extremely low risks associated with daily use of hydroxyurea, it is only sparingly prescribed in adult patients and is not yet approved for use in children [21].

\section{Effect of anaesthesia on sickle cell disease patients}

During surgical procedures undertaken in SCD patients under general anesthesia, severe anemia can be exacerbated or triggered from reduction in blood volumes compounded by low oxygen capacity of a sickle cell disease patient's blood. This in turn leads to a greatly reduced oxygenation throughout the body [15]. This further exposes the patient to complications that could result from de-oxygenation and dehydration. Stress, hypoxia, acidosis and infection could all provoke more sickling through interleukins, vasoconstriction, and nitric oxide (NO) pathways. When the red cell is exposed to these factors it undergoes conformational changes leading to polymerization and formation of the sickle shape. This polymerized red cell is rigid, undeformable and can be easily haemolysed with further aggravation of haemolytic state.

\section{Anticoagulation in SCD}

Sickle cell disease is often associated with hyper-coagulable state, even when there is no injury or tears triggering such process [22]. For this reason, heparin might be used for management of the disease for standard care and also in post-operative settings, where natural and necessary coagulative responses could cascade into detrimental levels of coagulation factors [22]. There is some risk involved in the use of heparin following surgery as it can aggravate bleeding, however, with proper monitoring and care these risks could be easily mitigated in hospital settings [22].

\section{Literature Review}

Review of literature was performed using Cochrane collaboration search engine, Google search and UCL library web sites. Additionally haematology text books and haemoglobinopathy references were also obtained on sickle cell disease, transfusion requirement in sickle cell disease, types of surgeries and outcome of different transfusion regimens.

The perioperative complications associated with sickle cell disease have led to exploration of different transfusion and transfusionexchange methods to minimise risks to patients undergoing surgery. However, there is no medical consensus in this area $[6,8,15,17,18]$. Some studies showed that transfusion does not cause any statistically significant improvement in post-operative success when compared to surgery in sickle cell disease without transfusion $[6,8,15]$. Other studies comparing aggressive versus conservative transfusion therapies found little to no difference between these approaches, but implied a difference after transfusion therapy and their complete preoperative absences $[6,23]$. Preoperative blood transfusions are therefore, frequently given to prevent and reduce perioperative complications. But even when correctly used, they are not without complications.

The first study which compared an aggressive transfusion regimen in SCD (decreasing sickle haemoglobin to less than 30\%) to a conservative transfusion regimen (increasing haemoglobin to $10 \mathrm{~g} /$ $\mathrm{dL}$ ) was undertaken in 604 elective operations in sickle cell disease by [6]. The conservative regimen was found to be as effective as the aggressive regimen in preventing perioperative complications, and was associated with fewer transfusion related adverse events. The second study which compared a preoperative transfusion group to a group receiving standard care did not show any advantage of preoperative transfusion. Blood transfusions could be full or partial in type [24]. They could be linked to adverse events such as the development of antibodies to foreign red blood cells, iron overload, post-operative infection rates and length of hospital stay. Two large studies with 920 people were reviewed. One study compared full transfusion to partial transfusion. This showed no difference between the two regimens in preventing complications immediately after surgery, but partial transfusion was linked to fewer adverse events. The second study which compared transfusion to standard care did not show any advantage of transfusion. Both studies reported a range of complications related to transfusion regime. [6].

There is considerable difference in opinion and evidence regarding the utility and benefits, if any, of perioperative and/or preoperative transfusions in sickle cell disease patients undergoing surgery. There are also different transfusion techniques with varying degrees of efficacy as shown in different studies. These techniques could basically be divided into simple transfusions, consisting of simple "top ups" transfusion (STX) and blood packing to ensure adequate oxygen delivery before and after surgery, and exchange transfusions (ETX) in which patients are bled first and subsequently receive specific amounts of saline and packed red blood cells, which raises volume of blood and also the proportion of healthy red blood cells $[8,15]$.

Recommendations developed for SCD patients undergoing surgical procedures requiring general anaesthesia are largely empirical based on clinical outcome as there are no RCTS comparing transfusion with no transfusion. Preoperative blood transfusion is recommended in all patients undergoing moderate to high risk procedures. This could be achieved by top up blood transfusion aiming to attain a $\mathrm{Hb}$ level of $10 \mathrm{~g} / \mathrm{dl}$. The aggressive regimen is required for older adults and those with pulmonary or cardiac diseases, aiming to reduce the HbS level to less than $30 \%$. The younger patients undergoing low risk procedures are allowed to proceed without preoperative transfusion therapy [25].

A comparative study of simple top up transfusion versus exchange transfusion was studied in 1995 in 551 patients by [25] who were assigned randomly to receive either type of transfusion. The aim was to achieve a $\mathrm{Hb}$ level of $10 \mathrm{~g} / \mathrm{dl}$ preoperatively. Patients were randomised to a conservative approach using top up transfusion method to raise the $\mathrm{Hb}$ level to $10 \mathrm{~g} / \mathrm{dl}$ or aggressive transfusion to decrease $\mathrm{HbS}$ level to less than $30 \%$. The surgical interventions were classified into low risk (like inguinal hernia), medium risk (such as intra operative abdominal procedures) or high risk (e.g. intracranial procedure) [25]. There was no significant difference between the two groups in the post-operative sickle cell-related complications. However in this study, exchange transfusion (EX TX) showed more haemolytic transfusion reaction and red cell alloimmunisation. Although simple transfusion could bring the $\mathrm{Hb}$ to the level of $10 \mathrm{~g} / \mathrm{dl}$, exchange transfusion (EX TX) was still indicated in high-risk operations and in patients with combined heterozygous of $\mathrm{Hb} \mathrm{S}$ and $\mathrm{Hb} \mathrm{C}$ (HbSC) diseases [23,26].

\section{Aims of the Study}

- To evaluate the relative risks and benefits of preoperative blood transfusion regimens in patients with sickle cell disease attending King Fahd Hospital.

- To determine outcome of local hospital guideline on complications in the intra operative and postoperative periods. 
- To evaluate role of medical therapy such as proper hydration, oxygenation, antibiotics and anticoagulation during and after surgery and patient safety.

\section{Methods}

\section{Study design}

This retrospective study was conducted at King Fahd Hospital, Jeddah, Western Saudi Arabia between April 2005 and May 2010. The study was approved by hospital Ethics committee.

King Fahd hospital in Jeddah is the largest institution in the western region of Saudi Arabia. It is 600 bed hospital that cares for adult patients in the medical, surgical, orthopaedic, dental, ear nose and throat (ENT) and rehabilitation service. It is one of the major referral centers in the ministry of health covering the western region of Saudi Arabia.

This hospital is the main centre for the management of patients with SCD in the western region. There are around 400-600 sickle cell disease patients registered for medical care. The annual admissions of sickle cell patients are around $240-300$, which constituted $80 \%$ of the in-patient admissions of the hematology department.

\section{Patient recruitment method}

The study's population consisted of patients with sickle cell disease undergoing variety of different surgical procedures, which were performed at King Fahd Hospital.

The department received around 350-400 consultations from medical and other subspecialty yearly. The preoperative consultations for sickle cell patients undergoing surgery are around 7\% annually.

Seventy-five individuals with SCD (Hb-SS) who underwent surgeries under anaesthesia were included in this study.

Six patients with other inherited hemolytic disorders like sickle cell trait, SB thalassaemia and those who underwent ERCP were excluded from the study group.

\section{Hospital protocol}

The haematology department, decide whether SCD patients undergoing elective or emergency surgeries should be transfused preoperatively or not.

Local guidelines for the indication and selection of pre-operative transfusion regime in SCD patients are in place as shown in (Figure 1).

The need and type for pre-operative transfusion was determined by result of $\mathrm{CBC}$. Aim of pre-operative transfusion was to achieve $\mathrm{Hb}>10$ $\mathrm{g} / \mathrm{d}$. The $\mathrm{HbS} \%$ was assessed only in patients undergoing major surgery.

According to our hospital protocol (Figure 1) the patients were classified into three groups based on the risk of operation. Low risk group are those who had minor surgeries like dental extraction and incision and drainage for abscess. The patients in this group required either local anesthesia or general anesthesia that last for less than 30 minutes. The advice for this group was no need for transfusion, if $\mathrm{Hb}$ level is $>8 \mathrm{~g} / \mathrm{dl}$ [27].

The second group was moderate risk group who required anesthesia of more than 30 minutes but less than two hours, such as laparoscopic cholecystectomy and laparoscopic splenectomy. In this case, the patient's haemoglobin level determined the selection of transfusion type. If $\mathrm{Hb}$ level below or equal to $8 \mathrm{~g} / \mathrm{dl}$, the patient had a simple top up transfusion (STX) of 2 units, if $\mathrm{Hb}$ level above $8-10 \mathrm{~g} / \mathrm{dl}$, the patient had a partial exchange transfusion by removing one unit and given 2 units. Complete exchange blood transfusion (CETX) was given if the Hb level above $10 \mathrm{~g} / \mathrm{dl}$ [16].

The high risk groups are those with history of recurrent vasoocclusive crises and/or history of acute chest syndrome who underwent a surgical procedure that require prolonged anesthesia of more than two hours. These procedures include joint replacement, central nervous system intervention and eye surgery. For those groups advice was to give aggressive exchange transfusion in order to keep $\mathrm{Hb} \mathrm{S}$ level around 30\% [12].

In post-operative period, a multidisciplinary approach was adopted

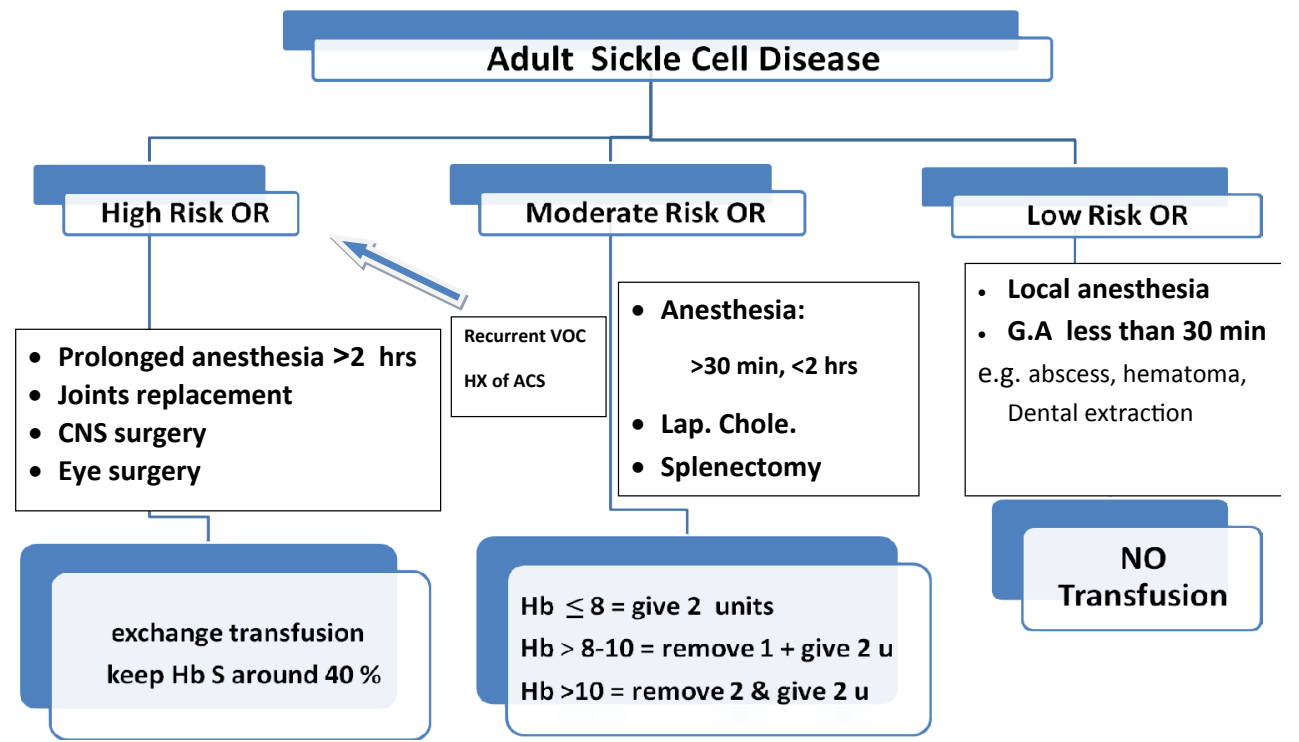

Figure 1: KFH hospital guidelines for SCD patients. 
involving haematologist, anaesthetist and surgeon. All patients were nursed in the general surgical, orthopedic or ENT wards depending on the type of operation. Upon admission, IV fluid, prophylactic heparin and antibiotics were recorded. We used manual method for the time being at KFH for exchange transfusion as shown in (Figure 2) [24].

\section{Data collection}

Patient records were accessed in accordance to privacy laws and ethical standards for use of private medical information. The records were rendered anonymyised prior to primary research as per hospital protocol. The records were accessed electronically first to identify SCD patients who had undergone a surgical treatment during the study period. The hard copies of the 75 patients who were included in the study were obtained.

The data was collected from the medical records including the age, sex, height and weight, history of vaso-occlusive crises and acute chest syndrome. Additionally, the smoking status of the patient, duration of admission, history of using hydroxyurea was also recorded. The haematology advice regarding the type of transfusion modality or the type of transfusion selected for the patient was recorded.

Furthermore, information on the type of transfusion selected in the peri-operative period was also collected. The details of operation were documented including the operative duration, intra-operative bleeding and complications.

Number and severity of perioperative and postoperative complications including bleeding, fever, vaso-occlusive crises, infection, use of antibiotics, and anticoagulation therapy were also collected.

The use of hydroxyurea and postoperative heparin prophylaxes were also included in the recorded observation. The $\mathrm{Hb}$ level on admission, $\mathrm{Hb}$ post transfusion and post-operative $\mathrm{Hb}$ levels were recorded as well as the renal function and liver functions test results.

\section{Statistical methods}

Standard software was used for this purpose, with the bulk of the analysis conducted using the latest available version of the SPSS software mist typically used for statistical analysis in such cases. Encryption of data was utilized to some degree, though to a fairly minimal extent as there was not considered to be a high risk of unauthorized access nor of potential damage caused by the unauthorized release of any of the data used in the study, as no personally identifying information was entered into the software program alongside the individual data points that formed the primary data for this research.

The data of patient's details, transfusion type, risk factors and postoperative outcome were expressed intables using SPSS v18.

\section{Result}

\section{Patient characteristics}

This study included 75 SCD patients with the median age of 24

\section{Manual Red Cell Exchange}

A. Calculate exchange volume :

\section{Body weight ( kg ) x $75 \times 0.4$}

B. Perform adult manual exchange as follows:

- Bleed $500 \mathrm{cc}$ and then infuse $500 \mathrm{cc}$ saline

- Bleed $500 \mathrm{cc}$ and then infuse 2 units packed red

- Repeat steps 1 and 2 until volume of packed cells administered is equal to planned exchange volume

(up to three or even four repeats for large adults)

If patient has a starting hemoglobin close to or more than 10

- Consider a $500 \mathrm{~mL}$ bleed at the end $\underline{O R}$

- Infuse 1 unit instead of 2 units in the second cycle of 3 steps

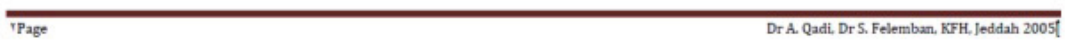

Figure 2: Red cell exchange protocol.

\begin{tabular}{|c|c|c|c|c|}
\hline Variable & Total no $(\mathrm{N}=75)$ & Transfused group $(n=52)$ & Non-Transfused group $(n=23)$ & $P$ value \\
\hline Age (y) & $24(14-49)$ & $24.5(14-42)$ & $23(14-49)$ & NS \\
\hline \multicolumn{5}{|l|}{ Sex } \\
\hline Male n (\%) & $34(45.3 \%)$ & $22(42.3 \%)$ & $12(52.2 \%)$ & NS \\
\hline Female $\mathrm{n}(\%)$ & $41(54.7 \%)$ & $30(57.7 \%)$ & $11(47.8 \%)$ & \\
\hline Height (cm) & $158(145-186)$ & $158(145-186)$ & $156(145-174)$ & $<0.01$ \\
\hline Weight (Kg) & $53(30-70)$ & $53(30-70)$ & $53(30-62)$ & $<0.01$ \\
\hline Pre-transfusion & $9.5(4.5-13.3)$ & $9.0(4.5-13.3)$ & $9.5(8-11)$ & $<0.01$ \\
\hline \multicolumn{5}{|l|}{$\mathrm{Hb}(\mathrm{g} / \mathrm{dl})$} \\
\hline Post-transfusion $\mathrm{Hb}$ (g/dl) & $10(7.8-12.4)$ & $10.9(8-12.4)$ & $9.5(8-11)$ & NS \\
\hline
\end{tabular}

Table 1: Demographic, clinical parameters of the studied patients. 
Citation: Felemban SMR, Bajoria R, Alsawaf A, Chatterjee R, Qadi Al, et al. (2017) The Outcome of Preoperative Transfusion Guideline on Sickle Cell Disease Patients at King Fahd Hospital-Jeddah (KSA). J Blood Disord Transfus 8: 381. doi: 10.4172/2155-9864.1000381

Page 6 of 10

\begin{tabular}{|l|c|c|}
\hline Type of transfusion & Frequency & Percent (\%) \\
\hline No transfusion (NTX) & 23 & 30.7 \\
\hline Top up transfusion (STX) & 20 & 26.7 \\
\hline Complete exchange transfusion (CETX) & 19 & 25.3 \\
\hline Partial exchange transfusion (PETX) & 13 & 17.3 \\
\hline
\end{tabular}

Table 2: The frequency of transfusions types of the studied patients.

(range 14- 49) years, and there were 34 males and 41 females. As shown in Table 1, the median height was 158 (range 145-186) $\mathrm{cm}$ and the median weight was 53 (range 30-70) $\mathrm{Kg}$. The median pre-transfusion Hb level was 9.5 (range 4.5-13.3) g/ dL and the median post transfusion $\mathrm{Hb}$ level was 10 (range 7.8-12.4) g/dL.

Out of 75 patients, 52 received blood transfusion in the preoperative period and Twenty-three patients were not transfused as majority had minor surgical procedures. The difference between transfused and non-transfused group were not significant as regard to the age, sex and post transfusion $\mathrm{Hb}$, while it was shown to be highly significant in the height $(\mathrm{P}<0.01)$, weight $(\mathrm{P}<0.01)$ and pre-transfusion Hb level $(\mathrm{P}<0.01)$

Table 2 Shows that out of 52 patients who received perioperative transfusion, 20 patients (26.7\%) had simple top up transfusion (STX), 19 (25.3\%) had complete exchange transfusion (CETX), and $13(17.3 \%)$ had partial exchange transfusion (PETX).

\section{Pre-operative risk factors in transfused and non-transfused patients}

Table 3 demonstrates the distribution of risk factors in the studies SCD patients. As showed in this table, 70 (93.3\%) patients were smokers while only $5(6.7 \%)$ were nonsmokers. The SCD patients who had history of infrequent vaso-occlusive crises of less than 6 times per year were shown to be $2(2.7 \%)$ patients, while the SCD patients who had history of vaso-occlusive crises of more than 6 times per year were $73(96.7 \%)$.

There were 69 (92\%) who had no history of preoperative acute chest syndrome (ACS) while the SCD with history of preoperative acute chest syndrome (ACS) were 6 (8\%). Previous history of transfusion recorded in $50(72.5 \%)$ and there were $19(27.5 \%)$ with no previous history of transfusion. The history of patients who were on hydroxyurea were $20(26.7 \%)$ and there were $55(73.3 \%)$ with no previous history of hydroxyurea.

The use of heparin prophylaxis was recorded in $21(28 \%)$ and there were $54(72 \%)$ with no heparin prophylaxis in the postoperative period.

The difference between transfused and non-transfused group were not significant as regards to the history of smoking, preoperative acute chest syndrome, history of transfusion and history of hydroxyurea, while it was shown to be highly significant in those who had history of vaso-occlusive crises $(\mathrm{P}<0.05)$ and history of given heparin prophylaxis in the postoperative period $(\mathrm{P}<0.05)$.

\section{Types of surgical interventions in studied patients}

Table 4 shows the types of surgical intervention in transfused and non-transfused group of patients. The number of patient's undergone laparoscopic cholecystectomy (LCS) 35 (46\%), Total hip replacement (THR) 9 (12\%), adeno-tonsellectomies (ADT) 14 (18.7\%), laparoscopic splenectomy 5 (6.7\%), Open reduction with internal fixation (ORIF) 9 (12\%), abdominal surgery 3 (4\%), incision and drainage (I \& D) 5 (6.7\%), tissue biopsy 3 (4\%), AV fistula $1(1.3 \%)$ and cystolithotrypsy at $1(1.3 \%)$.

\begin{tabular}{|c|c|c|c|c|}
\hline Variable & $\begin{array}{l}\text { Total no } \\
(\mathrm{N}=75)\end{array}$ & $\begin{array}{c}\text { Transfused } \\
\text { group }(\mathrm{N}=52)\end{array}$ & $\begin{array}{c}\text { Non-transfused } \\
\text { group }(\mathrm{N}=23)\end{array}$ & $P$ value \\
\hline \multicolumn{5}{|l|}{ Smoking } \\
\hline Yes & $5(6.7 \%)$ & $5(9.6 \%)$ & 0 & NS \\
\hline No & $70(93.3 \%)$ & $47(90.4 \%)$ & $23(100 \%)$ & \\
\hline \multicolumn{5}{|c|}{ Pre-operative VOC } \\
\hline Frequent & $73(96.7 \%)$ & $52(100 \%)$ & $21(91.3 \%)$ & $<0.05$ \\
\hline Infrequent & $2(2.7 \%)$ & 0 & $2(8.7 \%)$ & \\
\hline \multicolumn{5}{|c|}{ Pre-operative ACS } \\
\hline Present & $6(8 \%)$ & $5(9.6 \%)$ & $1(4.3 \%)$ & NS \\
\hline Absent & $69(92 \%)$ & $47(90.6 \%)$ & $22(96 \%)$ & \\
\hline \multicolumn{5}{|l|}{$\begin{array}{l}\text { Previous } \\
\text { transfusion }\end{array}$} \\
\hline Present & $56(72.5 \%)$ & $40(76.9 \%)$ & $16(69.6 \%)$ & NS \\
\hline Absent & $19(27.5 \%)$ & $12(23.1 \%)$ & $7(30.4 \%)$ & \\
\hline \multicolumn{5}{|c|}{ Hydroxyurea } \\
\hline Given & $20(26.7 \%)$ & $16(30.8 \%)$ & $4(17.4 \%)$ & NS \\
\hline Not given & $55(73.3 \%)$ & $36(69.2 \%)$ & $19(82.6 \%$ & \\
\hline \multicolumn{5}{|l|}{ Heparin } \\
\hline Given & $21(28 \%)$ & $18(34.6 \%)$ & $3(13 \%)$ & $<.05$ \\
\hline Not given & $54(72 \%)$ & $34(65.4 \%)$ & $20(97 \%)$ & \\
\hline
\end{tabular}

Table 3: Risk factors in transfused and non- transfused patients.

\begin{tabular}{|c|c|c|c|}
\hline Surgery & $\begin{array}{c}\text { Total no } \\
\mathbf{( N = 7 5 )}\end{array}$ & $\begin{array}{c}\text { Transfused } \\
\text { group (N=52) }\end{array}$ & $\begin{array}{c}\text { Non-transfused } \\
\text { group (N=23) }\end{array}$ \\
\hline $\begin{array}{c}\text { Laparoscopic chole- } \\
\text { cystectomy }\end{array}$ & $24(32 \%)$ & $23(44.2 \%)$ & $1(4.3 \%)$ \\
\hline THR & $9(12 \%)$ & $9(17.3 \%)$ & 0 \\
\hline Adeno-tonsellectomies & $14(18.7 \%)$ & $8(15.4 \%)$ & $6(26.1 \%)$ \\
\hline Incision and drainage (I\&D) & $5(6.7 \%)$ & 0 & $5(22 \%)$ \\
\hline Tissue biopsy & $3(4 \%)$ & 0 & $3(13 \%)$ \\
\hline ORIF & $9(12 \%)$ & $4(7.7 \%)$ & $5(21.7 \%)$ \\
\hline Cysto-lithotripsy & $1(1.3 \%)$ & 0 & $1(4.3 \%)$ \\
\hline Abdominal surgery & $3(4 \%)$ & $3(5.8 \%)$ & 0 \\
\hline Laparoscopic Splenectomy & $5(6.7 \%)$ & $5(9.6 \%)$ & 0 \\
\hline CNS surgery & $1(1.3 \%)$ & 0 & $1(4.3 \%)$ \\
\hline AV fistula & $1(1.3 \%)$ & 0 & $1(4.3 \%)$ \\
\hline Total & 75 & 52 & 23 \\
\hline
\end{tabular}

Table 4: Types of surgery in transfused and non-transfused patients.

\section{Post-operative outcome following surgery}

Table 5 demonstrates the distribution of clinical parameters and its relation to the different type of transfusion. As you can see the frequency of non-transfused SCD (NTX) patients who develop postoperative fever are $6(26 \%)$, post-operative VOC were $6(26 \%)$ and non has developed post-operative ACS. The frequency of SCD patients who received simple top up transfusion (STX) and develop post-operative fever are $3(15 \%)$, post-operative VOC were $1(5 \%)$, and post-operative ACS $2(10 \%)$

The frequency of complete exchange transfusion (CETX) SCD patients who develop post-operative fever are $3(15 \%)$, post-operative VOC were $5(26.3 \%)$, no patient has developed post-operative ACS 0 and 7 (37\%) of patients had prolonged length of hospital stay of more than one week. Lastly, the frequency of SCD patients who had partial exchange transfusion (PETX) and develop operative VOC were 3 (15\%), and no patient has developed post-operative fever or postoperative ACS.

There was no significant difference between the three subtypes of transfusion regimen as regards the presence or absence of postoperative fever, VOC, and ACS. 
Citation: Felemban SMR, Bajoria R, Alsawaf A, Chatterjee R, Qadi Al, et al. (2017) The Outcome of Preoperative Transfusion Guideline on Sickle Cell Disease Patients at King Fahd Hospital-Jeddah (KSA). J Blood Disord Transfus 8: 381. doi: 10.4172/2155-9864.1000381

Page 7 of 10

\section{Effect of transfusion on length of stay}

Table 6 showed the relation between the lengths of stay in the transfused and non-transfused group. The patients who had prolonged length of hospital stay of more than one week were 2 (26\%) of nontransfused SCD (NTX) patients, 10(50\%) of SCD patients who received simple top up transfusion (STX), 7(37\%) patients who had complete exchange transfusion (CETX ) SCD patients and 3 (33\%) of patients who had partial exchange transfusion (PETX). The result were not

\begin{tabular}{|c|c|c|c|c|c|c|}
\hline Variable & $\begin{array}{c}\text { Total no } \\
(\mathrm{N}=75)\end{array}$ & $\begin{array}{c}\text { NTX } \\
(n=23)\end{array}$ & $\begin{array}{c}\text { STX } \\
(n=20)\end{array}$ & $\begin{array}{c}\text { CTX } \\
(n=13)\end{array}$ & $\begin{array}{c}\text { PEX } \\
(n=19)\end{array}$ & $P$ value \\
\hline \multicolumn{7}{|c|}{ Post Op fever } \\
\hline Present & $12(16 \%)$ & $6(26 \%)$ & $3(15 \%)$ & $3(16 \%)$ & 0 & NS \\
\hline Absent & $63(84 \%)$ & $17(74 \%)$ & $17(85 \%)$ & $16(84 \%)$ & $13(100 \%)$ & \\
\hline \multicolumn{7}{|c|}{ Post Op VOC } \\
\hline Present & $15(20 \%)$ & $6(26 \%)$ & $1(5 \%)$ & $5(26.3 \%)$ & $3(23 \%)$ & NS \\
\hline Absent & $60(80 \%)$ & $17(74 \%)$ & $19(95 \%)$ & $14(73.7 \%)$ & $10(77 \%)$ & \\
\hline \multicolumn{7}{|c|}{ Post Op ACS } \\
\hline Present & $2(2.7 \%)$ & 0 & $2(10 \%)$ & 0 & 0 & NS \\
\hline Absent & $73(97.3 \%)$ & $23(100 \%)$ & $18(90 \%)$ & $19(100 \%)$ & $13(100 \%)$ & \\
\hline
\end{tabular}

Table 5: Clinical parameters and its relation to the different type of transfusion

\begin{tabular}{|c|c|c|c|c|c|c|}
\hline Variable & $\begin{array}{c}\text { Total no } \\
(\mathrm{N}=75)\end{array}$ & $\begin{array}{c}\text { NTX } \\
(n=23)\end{array}$ & $\begin{array}{c}\text { STX } \\
(n=20)\end{array}$ & $\begin{array}{c}\text { CTX } \\
(n=13)\end{array}$ & $\begin{array}{c}\text { PEX } \\
(n=19)\end{array}$ & $P$ value \\
\hline Length of stay & & & & & & \\
\hline$<1$ Week & $50(66.7 \%)$ & $17(74 \%)$ & $10(50 \%)$ & $12(63 \%)$ & $10(77 \%)$ & NS \\
\hline$>1$ week & 25 (33.3\%) & $6(26 \%)$ & $10(50 \%)$ & $7(37 \%)$ & $3(33 \%)$ & \\
\hline
\end{tabular}

Table 6: Effect of postoperative heparin prophylaxis on post-operative outcome.

\begin{tabular}{|c|c|c|c|c|}
\hline Variable & $\begin{array}{c}\text { Total no } \\
(\mathrm{N}=75)\end{array}$ & $\begin{array}{c}\text { Heparin given } \\
(n=54)\end{array}$ & $\begin{array}{l}\text { Heparin Not } \\
\text { given }(n=21)\end{array}$ & P value \\
\hline \multicolumn{5}{|l|}{ Post op fever } \\
\hline Present & $12(16 \%)$ & $6(11.1 \%)$ & $6(28.6 \%)$ & NS \\
\hline Absent & 63 (84\%) & $48(88.9 \%)$ & $15(71.4 \%)$ & \\
\hline \multicolumn{5}{|l|}{ Post op VOC } \\
\hline Present & $15(20 \%)$ & $5(9.2 \%)$ & $10(47.6 \%)$ & $<0.01$ \\
\hline Absent & $60(80 \%)$ & $49(90.7 \%)$ & $11(52.4 \%)$ & \\
\hline \multicolumn{5}{|l|}{ Post op ACS } \\
\hline Present & $2(2.7 \%)$ & $2(3.7 \%)$ & 0 & NS \\
\hline Absent & $73(97.3 \%)$ & $52(96.3 \%)$ & $21(100 \%)$ & \\
\hline \multicolumn{5}{|l|}{ Length of stay } \\
\hline$<1$ Week & $50(66.7 \%)$ & $42(77.8 \%) \%)$ & $8(38 \%)$ & $<0.01$ \\
\hline$>1$ week & $25(33.3 \%)$ & $12(22.2 \%)$ & $13(62 \%)$ & \\
\hline
\end{tabular}

Table 7: Effect of postoperative heparin prophylaxis on post-operative outcome.

\begin{tabular}{|l|c|c|c|c|}
\hline Variable & $\begin{array}{c}\text { Total no } \\
(\mathbf{N}=75)\end{array}$ & $\begin{array}{c}\text { Hydroxyurea } \\
\text { given (n=55) }\end{array}$ & $\begin{array}{c}\text { Hydroxyurea } \\
\text { Not given (n=20) }\end{array}$ & P value \\
\hline Post op fever & \multicolumn{5}{|c|}{} \\
\hline Present & $12(16 \%)$ & $6(11 \%)$ & $6(30 \%)$ & $<0.05$ \\
\hline Absent & $63(84 \%)$ & $49(89 \%)$ & $14(70 \%)$ & \\
\hline Post op VOC & \multicolumn{5}{|l}{} & \\
\hline Present & $15(20 \%)$ & $8(14.5 \%)$ & $7(35 \%)$ & $<.05$ \\
\hline Absent & $60(80 \%)$ & $47(85.5 \%)$ & $13(65 \%)$ & \\
\hline Post op ACS & & & & \\
\hline Present & $2(2.7 \%)$ & $2(3.6 \%)$ & 0 & NS \\
\hline Absent & $73(97.3 \%)$ & $53(96.4 \%)$ & $20(100 \%)$ & \\
\hline Length of stay & & & & \\
\hline$<1$ Week & $50(66.7 \%)$ & $43(78 \%)$ & $7(35 \%)$ & NS \\
\hline$>1$ week & $25(33.3 \%)$ & $12(33 \%)$ & $13(65 \%)$ & \\
\hline
\end{tabular}

Table 8: Effect of Hydroxyurea on postoperative outcome.

\begin{tabular}{|c|c|c|c|c|}
\hline Variable & $\begin{array}{c}\text { Total no } \\
(\mathrm{N}=75)\end{array}$ & $\begin{array}{c}\text { Pre-Op Hb }<10 \\
(n=36)\end{array}$ & $\begin{array}{c}\text { Pre-Op Hb }>10 \\
(n=39)\end{array}$ & $P$ value \\
\hline \multicolumn{5}{|c|}{ Post op fever } \\
\hline Present & $12(16 \%)$ & $9(25 \%)$ & $3(0.7 \%)$ & 0.001 \\
\hline Absent & $63(84 \%)$ & $27(75 \%)$ & $36(92.3 \%)$ & \\
\hline \multicolumn{5}{|c|}{ Post op VOC } \\
\hline Present & $15(20 \%)$ & $12(33.3 \%)$ & $3(0.7 \%)$ & 0.002 \\
\hline Absent & $60(80 \%)$ & $24(66.6 \%)$ & $36(92.3 \%)$ & \\
\hline \multicolumn{5}{|c|}{ Post op ACS } \\
\hline Present & $2(2.7 \%)$ & $2(5.6 \%)$ & 0 & NS \\
\hline Absent & $73(97.3 \%)$ & $34(94.4 \%)$ & $39(100 \%)$ & \\
\hline \multicolumn{5}{|c|}{ Length of stay } \\
\hline$<1$ Week & $50(66.6 \%)$ & $20(55.6 \%)$ & $30(77 \%)$ & NS \\
\hline >1 week & $25(33.3 \%)$ & $16(44.4 \%)$ & $9(23 \%)$ & \\
\hline
\end{tabular}

Table 9: Effect of Pre-operative $\mathrm{Hb}$ level on postoperative outcome.

significant between transfused and non-transfused patient neither in between the three subtypes of transfusion modalities.

\section{Effect of Hydroxyurea and heparin on postoperative outcome}

The effect of postoperative heparin prophylaxis on postoperative outcome as shown on Table 7 was highly significant in reducing the length of hospital stay $(\mathrm{P}<0.01)$ and the post-operative vaso-occlusive crises $(\mathrm{P}<0.01)$. There was no significant effect on the incidence of postoperative fever and episode of ACS.

Hydroxyurea was found to have significant effect on reducing the postoperative vaso-occlusive crisis $(\mathrm{P}<0.05)$, and postoperative fever $(\mathrm{P}<0.05)$ as shown in Table 8 . While the effect on postoperative ACS and length of hospital stay was not significant.

\section{Effect of Post transfusion haemoglobin on postoperative outcome}

Table 9 showed the effect of preoperative $\mathrm{Hb}$ level in transfused (i.e. post transfusion $\mathrm{Hb}$ level) and non-transfused group of patients on the post-operative outcome. The results were highly significant between haemoglobin $(\mathrm{Hb})$ level and development of postoperative fever $(\mathrm{P}<0.05)$ and VOC $(\mathrm{P}<0.05)$. There was no significant association between the $\mathrm{Hb}$ level and postoperative ACS and length of hospital stay.

\section{Discussion}

Many patients with sickle cell anemia require surgery during their life as a result of disease complications such as gall stones and avascular necrosis [18]. They frequently encounter serious complications postoperatively despite standard perioperative care [18]. Therefore, preoperative blood transfusions, that are shown to decrease the frequency of most post-operative complications in sickle cell disease patients, are also frequently advocated in clinical practice [18]. Elective surgery in sickle cell anemia patients is generally safe when performed by using the optimal care. This necessitates the presence of transfusion guidelines by a close cooperation among a multidisciplinary department including the medical, anesthesia, and surgical teams to reduce the risk of morbidity [18].

This study aimed to assess the outcome of our local hospital guidelines on selection of the optimum preoperative transfusion regimen based on several factors which might lower the likely occurrence of complications in the intra operative and postoperative periods $[14,18]$. Furthermore we aimed to provide further advice to 
minimise the need for transfusion by medical therapy in selected SCA patients [27]. Further recommendations were extended to ensure patient safety by providing proper hydration, oxygenation, antibiotics and anticoagulation before and after surgery [28].

\section{Transfusion regimen and risk factors}

In this study, amongst the seventy five patients who undergone surgeries, around seventy percent had pre-operative transfusions and thirty percent did not require transfusion. The non-transfused group included those who had minor surgical procedures. The differences in ages and genders between the two groups were not significant, while the difference in the heights and weights were statistically significant. Also there was a significant difference in the $\mathrm{Hb}$ level of the non-transfused group with the pre-transfusion $\mathrm{Hb}$ level of transfused group which was less significant when compared to the post transfusion $\mathrm{Hb}$ level. The significant differences in heights and weights could be attributed to the wider ranges of heights and weights of transfused patients.

Several preoperative transfusion regimens were used in this study to reduce the risk of perioperative complications in patients with SCD. The results of this study showed that twenty three patients were not transfused (NTX), twenty patients had single or repeated simple top up transfusions (STX), thirty two had exchange blood transfusions of which nineteen had complete exchange and thirteen had partial exchange transfusions respectively. Therefore, the majority of patients of the study group were transfused. These regimens were given 1-15 days before operation. However, at present there was no consensus regarding the benefit of preoperative transfusion in these patients $[17,18,15]$. In addition, the benefits of blood transfusion should always be weighed against the risks of infective agents, hemolysis, and alloimmunisation [29].

There was a significant difference between the pre-operative $\mathrm{Hb}$ level and the pre-transfusion haemoglobin level of the transfused group since most of these patient who had low Hb levels had simple transfusions $[28,30]$. Simple transfusions (STX) were useful in SCD patients as they added to the oxygen carrying capacity of the red cells, unless STX was accompanied by bleeding or rapid red cell destructions, when hemoglobin concentration and the viscosity of the blood increased [24]. Compared to the previous studies, those who had a near to 8-10 g/ $\mathrm{dl} \mathrm{Hb}$ level and were considered severely ill, based on a history of frequent hospital admissions with sickling crises, and presence of sickle-related complications such as acute chest syndrome or stroke and required partial exchange transfusion. Patients who had a $\mathrm{Hb}$ level of above $10 \mathrm{~g} / \mathrm{dl}$ needed complete exchange transfusion especially if they were going for a major surgery or a CNS surgery. Red cell exchange was most useful to address immediate complications of sickle cell disease.

Replacement of sickle cells by normal cells could help in prevention of further vaso-occlusion with rapid decrease in the rate of hemolysis which in turn could decrease liver processing enzymes of bilirubin pathway, and reduce damage to renal tubular cells and the scavenging of nitric oxide by free hemoglobin which was released by sickle cells [24].

The differences between the transfused and non-transfused groups in relation to risk factors were significant which included frequency of vaso-occlusive crises and the use of heparin therapy during admission. The other risk factors such as preoperative acute chest syndrome, history of previous transfusion and the use of hydroxyurea were not significant between the transfused and non-transfused groups. All patients with frequent history of vaso-occlusive crises were transfused.
Among the twenty one patients who receive heparin prophylaxis, eighteen had transfusion and only two from non-transfused groups.

Table 4 demonstrates the types of surgical intervention in transfused and non-transfused group of patients. The number of patient's undergone Laparoscopic cholecystectomy (LCS) 35 (46\%), Total hip replacement (THR) 9 (12\%), adeno-tonsellectomies (ADT) 14(18.7\%), laparoscopic splenectomy 5 (6.7\%), Open reduction with internal fixation (ORIF) 9 (12\%), abdominal surgery 3(4\%), incision and drainage (I \& D) 5 (6.7\%), tissue biopsy 3 (4\%), AV fistula 1 (1.3\%) and cystolithotrypsy at $1(1.3 \%)$.

Therefore, the majority of SCD patients who had Laparoscopic cholecystectomy (LCS) had transfusion and all patients who had total hip replacement have been transfused. This agreed with pervious study by Buck J et al. were the majority of patients undergone a hip replacement surgery received an exchange transfusion, and ear nose and throat procedures were mainly preceded by top-up transfusion or no transfusion. The non-transfused group include those with miner surgeries like incision and drainage, cystolithotrypsy, AV fistula, tissue biopsy and some of patients who had adeno-tonsellectomies and Open reduction with internal fixation (ORIF) [15].

\section{The outcome of selected transfusion regimen}

The outcomes of postoperative transfusion were studied according to the different type of transfusions. The results of this study showed no significant differences between the 3 subtypes of transfusion as regards the presence or absence of postop fever, postop VOC, postop ACS as well as the length of stay. These data were in agreement with a similar study [18]. Simple top up transfusion and exchange transfusion regimes were compared in 551 patients who were assigned to randomly receive either types of transfusion.

The aim of exchange transfusion (EXTX) was to achieve a $\mathrm{Hb}$ level of $10 \mathrm{G} / \mathrm{dl}$ preoperatively. The results showed no significant differences in the two groups in the post-operative sickle cell-related complications [18]. Exchange transfusion (EXTX) was associated with a higher incidence of haemolytic transfusion reactions and red cell alloimmunisations [18]. Although simple transfusion could bring the $\mathrm{Hb}$ level to $10 \mathrm{~g} / \mathrm{dl}$, exchange transfusion (EXTX) was still indicated in high risk operations and for patients with combined heterozygosities of $\mathrm{Hb} \mathrm{S}$ and $\mathrm{Hb} \mathrm{C}$ (HbSC) $[18,26]$.

\section{Role of heparin prophylaxis}

Our study showed that postoperative heparin prophylaxis was highly significant in reducing the length of hospital stay and the postoperative vaso-occlusive crises. There was no significant effect on the incidence of post- operative fever and episode of ACS. Our data were consistent with published findings that heparin prophylaxis was associated with reduction in severest pain scores, overall duration of painful crisis, and duration of hospitalization [31]. This could be explained by the fact that sickle cell disease (SCD) was characterized by endothelial dysfunction which triggered erythrocyte polymerization [32]. The investigators suggested that there was obstruction of the arterioles by sickled erythrocytes which resulted from combined effects of increased adhesion molecule expression on red blood cells endothelial cells which interacted with white blood cells, increased cytokines, enhanced micro-vascular thrombosis and resulted in endothelial damage [32]. The adhesion of sickle erythrocytes to vascular endothelium was important for vascular occlusion [33].

Sickle cell disease was considered as a hyper-coagulation state, even when there was no obvious history of injury or tear to trigger such a 
coagulation pathway [22,32]. For this reason, heparin could be a useful drug for management of the disease in standard care and also in postoperative settings, where natural and necessary coagulative responses could cascade into detrimental levels of coagulation [22]. However use of heparin was not risk free as it could lead to greater levels of bleeding post operatively. But with proper management and care these risks could easily be mitigated in hospital settings [22].

\section{Role of hydroxyurea on postoperative outcome}

We showed that hydroxyurea had a significant beneficial effect on reduction of the postoperative vaso-occlusive crisis and postoperative fever. However the effect of hydroxyl urea on postoperative ACS and length of hospital stay were not significant.

This was likely to be mediated by NO pathway which is a free radical and a potent vasodilator which played a major role in every aspect of SCD. This included reduction of platelet activation and adhesion receptor expression on the vascular endothelium, decrease of vascular smooth muscle proliferation, limitation of ischemia-reperfusion injury, which modulates endothelial proliferation and regulates inflammation. It is well, established that impaired NO bioavailability represent the central feature of endothelial dysfunction in SCD patients and contributes to the overlapping mechanisms of vasculopathy [32]

Hydroxyurea is a highly effective drug which increases NO generation, with reduction in hemolysis and increase in fetal $\mathrm{Hb}$ levels [32]. Additionally, the hematological effects of hydroxyurea treatment included increase in the overall concentration of hemoglobin level in the blood and the mean corpuscular volumes allowing for a greater increase in blood flow, with reduced white blood cell count, absolute neutrophil count (ANC), absolute reticulocytes counts, and reduced lactate dehydrogenase (LDH) levels. Also morphological changes occur in red cells that reduce the number of harmful deformability of the red blood cells which is the hallmark of sickle cell disease [21].

Our results also suggest that hydroxyurea could improve the haemoglobin concentration and therefore decrease the need for transfusion in selected patients, with beneficial effect in reducing white blood cells. These changes are possibly mediated by NO which regulates inflammation and has a beneficial effect on postoperative fever and vaso-occlusive crises.

\section{Role of Preoperative haemoglobin level on postoperative outcome}

In our study we found that there was no significant associations between the Hb level and postoperative ACS and length of hospital stay in our patients. The correlation appeared to be a negative here, implying that the higher the levels of hemoglobin following transfusion were less likely to be associated with postoperative complications. These results were in agreement with investigators who suggested that the target of $\mathrm{Hb}$ level of 9-11 g/dL in SCD patients was likely to be associated with reduced post-operative complications [18].

\section{Transfusion regimes to minimize the adverse outcome in SCD}

The protocol of transfusion used in this study was based on the current literature on the type of the disease, the risk factors and the type of surgery. A conservative preoperative transfusion regimen was aimed to bring target hemoglobin concentration to $9: 11 \mathrm{~g} / \mathrm{dl}$. Lack of availability of adequate RCT for comparison of preoperative transfusion to regimes without transfusion made the task a challenge. There are several recommendations for SCD patients undergoing surgical procedures requiring anesthesia $[12,16,34]$.
Preoperative blood transfusion is recommended in all patients undergoing moderate to high risk procedures. These patients could be prepared by top up blood transfusions aiming to attain a $\mathrm{Hb}$ level of 10 $\mathrm{g} / \mathrm{dl}$ [18]. An aggressive regimen is required for older adults and those with pulmonary or cardiac diseases, aiming to reduce the $\mathrm{Hb} \mathrm{S}$ level to less than $30 \%$ (34). Younger patients undergoing low risk procedure are allowed to proceed without preoperative transfusion therapy [25,27].

According to our hospital protocol, the patients were classified into three groups based on the risk of operation. Low risk group were those who had minor surgeries such as dental extraction and incision and drainage for abscess. The patients in this group required either local anaesthesia or general anaesthesia that last for less than 30 minutes. The advice for this group was no need for transfusion, taken in consideration the presence of acceptable haemoglobin level of more than $8 \mathrm{gm} / \mathrm{dl}$ [27].

The second group was moderate risk group who required anaesthesia of more than 30 minutes but less than two hours, such as laparoscopic cholecystectomy and laparoscopic splenectomy. In this case, the patient's haemoglobin level determined the selection of transfusion type. If $\mathrm{Hb}$ level was below or equal to $8 \mathrm{~g} / \mathrm{dl}$, the patient had a simple top up transfusion (STX) of 2 units, if $\mathrm{Hb}$ level above 8-10 $\mathrm{g} / \mathrm{dl}$, the patient had a partial exchange transfusion by removing one unit and given 2 units. Complete exchange blood transfusion (CETX) was given if the $\mathrm{Hb}$ level was above $10 \mathrm{~g} / \mathrm{dl}$ [16].

The high risk groups were those with history of recurrent vasoocclusive crises and/or history of acute chest syndrome who underwent a surgical procedure that required prolonged anaesthesia of more than two hours. These procedures included joint replacement, central nervous system intervention and eye surgery. For these groups patients were advised to have aggressive exchange transfusion in order to keep $\mathrm{Hb}$ S level to around $30 \%$ [12].

\section{Advantages and limitations of the study}

The main advantage of the study was the large referral centre of SCD where a retrospective audit could be undertaken. We used manual method for the time being at KFH for exchange transfusion [24]. This was relatively simple to undertake and was standardised and a cost effective regime.

However the retrospective nature of the study, small sample size after stratification into groups and lack of prospective planning did not allow us to collect the best data to consolidate clear cut guidelines. The main limitation of the study was the missing HBEP data which were available in many patients in the study. The documentation of various parameters were also missing from case records such as the exact history of previous TX and frequencies, the duration of hydroxyurea used prior to surgery. Also $\mathrm{HBEP}$ with $\mathrm{Hb} \mathrm{F} \%$ was not available in patients to compare the effect of $\mathrm{HU}$ and $\mathrm{Hb} \mathrm{F}$.

The lack of HbS level were due to unavailability of HPLC and also the HBEP were usually done once a week in our institution as it was difficult for a surgeon to wait for another week to get a result of pre-, post- transfusion level of HbS. Unless the patient was planned for major surgeries such as hip replacement, the monitoring of $\mathrm{Hb} \mathrm{S}$ level seemed impractical as it could potentially delay the management and prolong the hospital stay unnecessarily. Therefore, the practical approach was to use $\mathrm{Hb}$ level as a target in addition to other risk factors for selection of the suitable transfusion regimen as recommended by some investigators [28]. It has been shown in previous studies to be as effective as aggressive transfusion regimen in which the hemoglobin $\mathrm{S}$ level was lowered to $30 \%$ [18]. 


\section{Implications and Future Research}

This study could be extended in the future to include a large number of patients and prospectively outlined with clear cut aims, objectives and end points. With a large sample size it would be possible to compare transfusion versus non transfusion, and study each type of surgical operation with the outcome parameters, aggressive versus conservative transfusion if $\mathrm{Hb} \mathrm{S} \%$ is available in all patients.

The effect of hydroxyurea on the need of transfusion therapy and the outcome of operation needs to be further explored in the future. Also the use of heparin in sickle cell patient and its beneficial effects in reducing the post-operative crises and hospital stay would make heparin an essential medication for optimal care in SCD patients undergoing surgery.

There was also a need to standardise the monitoring and scoring of post-operative pain, especially as most of the patients who developed severe pains were those who had orthopaedic surgeries. Therefore, careful assessment of pain by a hematologist and a surgeon is pertinent to differentiate those of major orthopedic surgery from the vasoocclusive crises [8].

\section{Conclusion}

This study showed that our local hospital guidelines for preoperative transfusion therapy on SCD patients undergoing surgery, in the previous five years in our institution at King Fahd hospital in Jeddah, are safe and effective in reducing the hospital morbidity and mortality as compared to the studies done on the same field. However, the lack of $\mathrm{Hb} \mathrm{S} \%$ made the confirmation of conservative versus aggressive therapy impossible from these data. Also we wish to improve the blood bank facility in our institution to include antibody (Ab) screening and red cell typing, which is only provided by the reference laboratory. This facility is especially important for multi transfused patients with antibodies, in order to minimise alloimmunisation and to find compatible blood when needed.

Further recommendation is extended to ensure patient safety by providing proper hydration, oxygenation, antibiotics and anticoagulation during and after surgery.

\section{References}

1. Wang WC (2009) Sickle cell anaemia and other sickling syndromes. In: Greer JP, Foerster J, Rodgers GM et al. Wintrobe's Clinical Hematology $\left(12^{\text {th }}\right.$ edition), Lippincott Williams \& Wilkins, Philadelphia.

2. (2010) NIH. "Sickle cell disease. National institute of health: Genetics home reference.

3. Savitt TL, Goldberg MF (1989) Herrick's 1910 case report of sickle cell anemia. The rest of the story. JAMA 261: 266-271.

4. Lenfant A, Knight G, Moore G (2010) The pathology of the redblood cell: Part 2. Haem. Oxford Univ Press 156-159.

5. Hebbel RP (2005) Pathophysiology of sickle cell disease. In: Hoffman R, Benz E, Shattii S et al. Hematology: Basic principle and practice (4th Edition), Elsevier Churchill Livingstone, Philadelphia.

6. Hirst C, Williamson L (2001) Preoperative blood transfusions for sickle cell disease (Review). Cochrane Database Syst Rev 2: 1-23.

7. Davies SC, Gilmore A (2003) The role of hydroxyurea in the management of sickle cell disease. Blood Reviews 17: 99-109.

8. Al-Samak Z, Al-Falaki M, Pasha A (2008) Assessment of perioperative transfusion therapy and complications in sickle cell disease patients undergoing surgery. Middle East J Anesthesiol 19: 983-995.

9. Balney KD, Howard PR (2000) Basic and applied concepts of immunohematology. St Louis: Mosby 310-311.
10. Salamah MM, Mallouh AA, Hamdan JA (1989) Acute splenic sequestration crises in Saudi children with sickle cell disease.Ann Trop Paediatr 9: 115-117.

11. Davies SC, Oni L (1997) Management of patients with sickle cell disease. BMJ 315: 656-660.

12. Callum J (2008) Sickle cell disease transfusion and perioperative management. Division of Hamatology 1- 6.

13. (2012) WHO. Sickle cell anemia. World health organization: 59th world health assembly, 2006.

14. Lenfant C, Adams R, Arage KI (2002) The mangement of sickle cell disease. Division of blood disease and resource, National Institues of Health 58-163.

15. Buck J, Casbard A, Llewelyn C, Johnson T, Davies S, et al. (2005) Preoperative transfusion in sickle cell disease: a survey of practice in England. Eur $\mathrm{J}$ Haematol 75: 14-21.

16. Win N (2004) Blood transfusion therapy for haemoglobinopathies. In: Okpala IE. Practical management of haemoglobinopathies. (1 ${ }^{\text {st }}$ Edition), Oxford, Blackwelll Publishing 99-104.

17. Haberkern CM, Neumayr LD, Orringer EP (1997) Cholecystectomy in sickle cell anemia patients: Perioperative outcome of 364 cases from the national preoperative transfusion study. Blood 89: 1533-1542.

18. Vichinsky EP, Charles MD, Haberkern M (1995) A comparison of conservative and aggressive transfusion regimens in the perioperative management of sickle cell disease. N Eng J Med 333: 206-213.

19. Platt OS, Brambilla DJ, Rosse WF, Milner PF, Castro O, et al. (1994) Mortality in sickle cell disease. Life expectancy and risk factors for early death. $\mathrm{N}$ Engl J Med 330: 1639-1644.

20. Koshy M, Weiner SJ, Miller ST, Sleeper LA, Vichinsky E, et al. (1995) Surgery and anesthesia in sickle cell disease. Cooperative Study of Sickle Cell Diseases. Blood 86: 3676-3684.

21. Ware RE, Aygun B (2009) Advances in the use of hydroxyurea. Hematology Am Soc Hematol Educ Program

22. Ataga KI, Key NS (2007) Hypercoagulability in sickle cell disease: New approaches to an old problem. Hematology Am Soc Hematol Educ Program.

23. Vichinsky EP, Styles LA, Colangelo LH, Wright EC, Castro O, et al. (1997) Acute chest syndrome in sickle cell disease: Clinical presentation and course. Cooperative Study of Sickle Cell Disease. Blood 89: 1787-1792.

24. Swerdlow PS (2006) Red cell exchange in sickle cell disease. Hematology Am Soc Hematol Educ Program.

25. Crowther MA, Ginsberg J, Schunemann H (2008) Evidence-based Hematology Oxford: Wiley-Blackwell 246-247.

26. Okpala IE (2004) The concept of comperhensive care of sickle cell disease. In Okpala IE. Practical management of haemoglobinopathies. (1 ${ }^{\text {st }}$ Edition), Oxford Blackwell Publishing 1-8.

27. Al-Jaouni SK, Al-Muhayawi SM, Qari MH (2006) Randomized clinical trial to evaluate the safety of avoiding pre-operative transfusion in sickle cell anemia. Bahrain Med Bull.

28. Meshikhes AW, Abkari HA, Faraj AA, Al-Dhurais SA, Al-Saif O (1998) The safety of laparoscopic cholecystectomy in sickle cell disease: An update. Ann Saudi Med 18: 12-14.

29. Al-Mulhim AS1, Al-Mulhim AA (2009) Laparoscopic cholecystectomy in 427 adults with sickle cell disease: a single-center experience. Surg Endosc 23: 1599-1602.

30. Vichinsky EP, Neumayr LD, Haberkern C (1999) The perioperative complication rate of orthopedic surgery in sickle cell disease: Report of the National Sickle Cell Surgery Study Group. Am J Hematol 62: 129-138.

31. Qari MH, Aljaouni SK, Alardawi MS, Fatani H, Alsayes FM, et al. (2007) Reduction of painful vaso-occlusive crisis of sickle cell anaemia by tinzaparin in a double-blind randomized trial. Thromb Haemost 98: 392-396.

32. Morris CR (2008) Mechanisms of vasculopathy in sickle cell disease and thalassemia. Hematology Am Soc Hematol Educ Program.

33. Matsui NM, Varki A, Embury SH (2002) Heparin inhibits the flow adhesion of sickle red blood cells to P-selectin. Blood 100: 3790-3796.

34. Ritchard C, Carison B, Chambers L (2007) Practice guidelines for blood transfusion. A compilation from recent peer-reviewed literature. American Red Cross 16-20. 